\title{
Keynes e o Brasil
}

\section{Fernando J. Cardim de Carvalho ${ }^{1}$}

Há muitos anos é notada, com alguma surpresa, a forte influência do pensamento de Keynes e seus seguidores sobre o pensamento econômico brasileiro. Mesmo nos tenebrosos anos 1980, quando, especialmente no mundo acadêmico norte-americano, emergiu com força tão intensa quanto efêmera a chamada escolas dos Novos Clássicos, a comunidade acadêmica de economia no Brasil continuou cultivando a herança de grandes economistas como, mas não apenas, Keynes, Kalecki e Schumpeter, apenas para citar uns poucos.

Não cabe aqui ir muito longe especulando sobre as razões da permanência deste interesse, que se renova com a mesma força a cada nova geração de estudantes. É possível que economistas brasileiros se sintam naturalmente atraídos por correntes de pensamento que enfatizam as incertezas que cercam o futuro, a instabilidade da vida econômica, e a importância do papel do Estado na escolha dos caminhos que esta sociedade deverá trilhar no futuro, em contraste com o mundo encantado da sucessão de equilíbrios paretianos concebido pela ortodoxia. É também possível que a força das heterodoxias, em especial a keynesiana, se deva à existência no país de uma massa crítica de instrutores e pesquisadores praticantes dessas tradições que supere a impressão de isolamento e o desânimo que novos ingressantes no mundo acadêmico interessados nestas tradições enfrentam em outros países. É possível ainda que a existência de uma comunidade ativa e produtiva de economistas keynesianos simplesmente impeça que grupos ortodoxos mais dogmáticos consigam controlar como gostariam a alocação de verbas de pesquisa, discriminando formas diversas de pensamento, como ocorre especialmente, mas não exclusivamente, nos Estados Unidos. Sem negar a aceitação do pluralismo acadêmico por vários economistas ortodoxos, é difícil negar que a preservação da liberdade de reflexão acadêmica do Brasil sempre dependeu muito mais da força dos praticantes de tradições independentes do que da abertura intelectual da ortodoxia.

Por isso mesmo, isto é, pelo fato de que a abertura da comunidade acadêmica brasileira a idéias que fujam ao conformismo estreito do chamado mainstream é garantida não apenas pela capacidade intelectual dos pesquisadores heterodoxos, mas também pela percepção de que o preço da liberdade é a eterna vigilância, é que se coloca a necessidade, mais do que apenas a oportunidade da

(1) Professor do Instituto de Economia da Universidade Federal do Rio de Janeiro, Brasil. E-mail: fjccarvalho@uol.com.br.

Economia e Sociedade, Campinas, v. 17, Número especial, p. 569-574, dez. 2008. 
criação da Associação Keynesiana Brasileira (AKB). Seguindo o caminho aberto por outras associações de natureza semelhante, uma associação como essa deve ter dois objetivos centrais: congregar os praticantes de uma mesma tradição teórica de modo a permitir o surgimento de parcerias e colaborações que reforçam o seu potencial criativo; dar às visões mais importantes alimentadas por essa tradição a força dos números, aumentando continuamente sua capacidade de influenciar opiniões, dentro e fora do mundo acadêmico.

Ambos os objetivos são da maior importância no momento presente. A produção bibliográfica em intensidade acima da média no país de autores keynesianos permitiu que suas idéias se disseminassem amplamente no país. Um fator de enorme importância para a divulgação não apenas do pensamento keynesiano, mas de outras correntes heterodoxas igualmente, foi a existência, nas últimas décadas, de um periódico científico cuja sólida reputação é reconhecida mesmo por economistas ortodoxos, a Revista de Economia Política. Por outro lado, a intensa produção de livros, de autoria individual ou coletiva, veiculando debates sobre aspectos e aplicações da teoria keynesiana também contribuiu para espalhar essas idéias pelo país. Um dos resultados deste esforço foi o aparecimento de muitos pesquisadores individuais ou a formação de numerosos grupos de pesquisa sobre temas keynesianos em todo o país. Por esta razão, assim se definiu uma primeira demanda de criação de uma associação: pela possibilidade, ou, mais, pela necessidade de congregar pesquisadores individuais e grupos de pesquisa espalhados pelo Brasil, permitindo que esses grupos não apenas recebam informações, mas, e com muito maior importância, possam contribuir para o debate e para o avanço dos programas de pesquisa keynesianos.

Já a segunda função consiste em dar uma identidade pública para o keynesianismo, especialmente como doutrina de política econômica. Não se quer minimizar aqui a existência de divergências teóricas entre correntes keynesianas, nem se sugerir, implicitamente, que exista uma interpretação keynesiana privilegiada, da qual as outras sejam tributárias. Mas, para além de divergências teóricas ou conceituais, existem de fato alguns pressupostos comuns a praticamente todas as variantes do pensamento keynesiano, especialmente no que se refere à importância e a natureza da política econômica. Pode-se afirmar, com pouca, se alguma, hesitação, que qualquer pesquisador de afiliação keynesiana, qualquer que seja sua vertente teórica, compartilha um diagnóstico básico a respeito da inabilidade de economias empresariais em gerar e, principalmente, manter o pleno emprego dos recursos disponíveis e da força de trabalho. Mas a doutrina keynesiana não se esgota no diagnóstico, ela se estende à priorização do pleno emprego como objetivo de política econômica. Ela se estende também à identificação de quais são os instrumentos eficazes para que esse objetivo seja alcançado: a manutenção de níveis de demanda agregada elevados, que 
mantenham o produto efetivo da economia o mais próximo possível do potencial. Talvez mesmo um pouco acima do potencial para, com isso, estimular a realização de investimentos.

O keynesianismo é uma doutrina ativista, que preconiza a ação do Estado na promoção e sustentação do pleno emprego em economias empresariais. Ele dialoga, mas não se confunde com outras doutrinas, que se apóiam em princípios teóricos e prioridades políticas diferentes. Por outro lado, a teoria keynesiana, em parte como herança do seu próprio criador, tem como objeto o mundo real, de modo a ter bem claro que a construção de conceitos e modelos não é, de modo algum, um fim em si mesmo, mas um instrumento de pesquisa empírica e derivação de políticas de ação. Como todo instrumento, conceitos e modelos tendem a tornar-se obsoletos com o tempo, e têm de ser modernizados para que sua eficiência deva ser mantida. O keynesianismo, nos termos propostos por Schumpeter, em sua monumental história do pensamento econômico, é principalmente uma visão, mais do que um instrumento de análise.

Nesse sentido, dada a importância da participação ativa e permanente no debate público de política econômica, define-se a segunda função central de uma associação keynesiana: a construção da identidade política keynesiana, definindo seus princípios e dando-lhe, ao mesmo tempo, a força dos números, isto é, mostrando que tais idéias e proposições não se devem à fértil imaginação de acadêmicos isolados em torres de marfim, mas são, ao contrário, elementos de uma doutrina compartilhada por uma amplo número de pesquisadores.

\section{O pensamento keynesiano no Brasil}

Keynes foi introduzido na América Latina principalmente através de Raul Prebisch. O estruturalismo cepalino foi uma adaptação do keynesianismo, não apenas para as condições regionais da América Latina mas, principalmente, para a problemática do subdesenvolvimento, como, aliás, também se fazia em outros importantes centros difusores do pensamento keynesiano em países em desenvolvimento, como na Índia.

No Brasil, um dos primeiros expoentes do pensamento keynesiano, apesar de suas poucas referências explícitas a Keynes, foi Celso Furtado. Nessa direção, talvez sua obra mais influente tenha sido a Formação Econômica do Brasil, trabalho brilhante e seminal, de leitura fluente e impactante até o presente, imediatamente reconhecida como uma aplicação da abordagem macroeconômica proposta por Keynes à historiografia econômica. De qualquer forma, a escola cepalina, enquanto permaneceu ativa, representou um estímulo importante não só ao conhecimento das idéias de Keynes, mas à sua utilização em contextos diversos daqueles em que o autor as desenvolveu. 
Fernando J. Cardim de Carvalho

Naturalmente, Keynes também foi introduzido ao público brasileiro, como no resto do mundo, através do ecletismo da chamada Síntese Neo-Clássica. Várias gerações de estudantes de economia valeram-se do livro-texto de Paul Samuelson, onde o próprio rótulo foi popularizado e aprenderam a manipular modelos "keynesianos" como a IS/LM. Na verdade, embora o Economics, de Samuelson, tenha sido aposentado há muitos anos, as presentes gerações de estudantes de graduação em economia ainda aprendem o básico de sua teoria macroeconômica através dos modelos IS/LM.

Nas últimas duas a três décadas, já no contexto da recuperação da obra de Keynes e da crítica à síntese neo-clássica, duas escolas de pensamento tem-se dedicado ao seu estudo, em linhas paralelas, com vários pontos de contato, mas que permanecem largamente independentes. Uma escola, centrada principalmente no Instituto de Economia da UNICAMP, desenvolve uma linha de reflexão em que o estudo de Keynes de certa forma culmina uma trajetória iniciada com a crítica marxista às idéias cepalinas nos anos 1970. A crítica marxista levou a Kalecki e sua versão do princípio da demanda efetiva e chegou-se a Keynes e seus seguidores mais próximos especialmente pela atenção por eles dedicada a variáveis monetárias e financeiras na explicação da instável dinâmica de economias capitalistas.

A outra escola, chamada aqui, por falta de melhor termo, de vertente marshalliana, tem como centro o Instituto de Economia da UFRJ. Esta corrente de pensamento, que se apóia amplamente no pós keynesianismo norte-americano, liderado por autores como Paul Davidson e Hyman Minsky, contrasta Keynes prioritariamente à macroeconomia neo-clássica, mais que a Marx ou mesmo a Kalecki. Dois marcos no desenvolvimento desta escola foram, primeiro, o curso oferecido ainda na Universidade Federal Fluminense por Paul Davidson em 1987, que introduziu mais amplamente as idéias pós keynesianas no país e, segundo, o seminário realizado em 1997, na UFRJ, que trouxe ao Brasil pesquisadores como Nina Shapiro, Steve Fazzari, Philip Arestis, Gary Dimsky e Jan Kregel. Os últimos três, em particular, passaram a participar ativamente do desenvolvimento do keynesianismo no Brasil, escrevendo trabalhos em co-autoria com autores locais, participando de seminários e conferências no Brasil, etc.

Atualmente, vários centros acadêmicos mantêm importantes núcleos de pesquisa em economia keynesiana, em alguma de suas variantes. Encontramos pesquisadores ou grupos de pesquisa influentes nessa corrente na Universidade Federal do Rio Grande do Sul, na Universidade Federal de Minas Gerais e na Universidade de Brasília, além da UFRJ e da Unicamp. Seria impossível listar aqui todos os centros onde se abrigam pesquisadores keynesianos, até por desconhecimento do autor, mas não se pode deixar de citar a FGV de São Paulo, a Unesp de Araraquara, a UFPr e a UFF. Na verdade, como já se sugeriu, mapear a 
presença de pesquisadores keynesianos no Brasil deve ser um dos objetivos centrais da AKB.

\section{A AKB e o debate sobre política econômica no Brasil}

No curto prazo, talvez o papel mais importante da associação seja mesmo dar uma face definida às posições keynesianas a respeito das opções de política econômica no Brasil. Após os três mandatos presidenciais marcados por uma política econômica liberal, os dois de Cardoso e o primeiro de Lula da Silva, a substituição de Pallocci no Ministério da Fazenda, ainda que em função de escândalos de natureza policial, ao invés da crítica política, abriu novas possibilidades em um debate em que, até então, mesmo um governo de esquerda era representado por economistas liberais.

Nesse sentido, a acepção em que se deve tomar o termo "keynesiano" para efeitos de associação deve, a meu ver, ser ampla e apoiada mais na concordância com a doutrina keynesiana que em uma ou outra versão da teoria keynesiana. $\mathrm{O}$ termo doutrina é utilizado no mesmo sentido referido anteriormente. É algo mais do que a visão, no sentido schumpeteriano, porque envolve não apenas as intuições fundamentais a respeito de como funciona uma economia empresarial, incluindo também um posicionamento político e uma abordagem estratégica.

Keynes, no último capítulo de sua obra magna, A Teoria Geral do Emprego, Juros e Moeda, propôs que economias modernas enfrentam dois grandes problemas. O primeiro é a concentração excessiva de renda e riqueza, que não se justifica nem mesmo pelas regras éticas do capitalismo, segundo as quais diferenças de renda atribuíveis a disposição a risco, animal spirits ou qualquer outro argumento desta natureza, são justificáveis e mesmo socialmente úteis. Para este mal, os remédios de Keynes são relativamente simples: taxar progressivamente as rendas mais elevadas e gastar na provisão de bens públicos.

O outro problema central é a incapacidade dessas economias de manter o pleno emprego, mesmo quando o alcançam eventualmente. No caso, o diagnóstico central é o da insuficiência de demanda privada agregada, isto é a falta de disposição de consumidores e investidores privados em gastar o necessário em bens de consumo e capital que justifique, aos olhos das empresas, produzir no limite de sua capacidade.

Não cabe aqui discutir as razões pelas quais se pode esperar uma demanda efetiva insuficiente para justificar o pleno emprego. A literatura sobre esse ponto é vasta, para a qual mesmo este autor já contribuiu no passado. O que importa frisar aqui é que, como no caso do problema da concentração excessiva de renda e riqueza, a saída preconizada pela doutrina keynesiana se dá através da ação do Estado. A doutrina keynesiana, como argumentado acima, define um 
posicionamento político, a defesa do pleno emprego como objetivo maior da política econômica, e uma abordagem estratégica, onde a ação do Estado deve se dar na direção do estímulo à demanda privada através de políticas macroeconômicas, como as políticas fiscal, monetária e de rendas.

Como Joan Robinson defendeu nos seus últimos anos, é possível pensarse em uma forma keynesiana de socialismo. Outros autores defenderam uma visão mais conservadora dentro do espectro keynesiano onde estruturas empresariais são preservadas e apenas a demanda agregada é administrada de modo a obter e manter o pleno emprego. A tradição social-democrata européia, por exemplo, se apóia amplamente em Keynes. Para ambos os extremos, e a coleção de visões intermediárias, um traço comum é, como sugerido, a noção de que cabe à sociedade, através do Estado, manter o pleno emprego como prioridade, para além de qualquer tergiversação, e redistribuir renda e riqueza através do sistema de impostos e gastos públicos. Por outro lado, novos problemas e restrições surgiram nas últimas décadas, em especial o crescimento da influência dos mercados financeiros sobre as decisões de política econômica. O processo de globalização, em especial, novamente, a globalização financeira, também contribuiu para um estreitamento aparente do espaço de atuação do Estado. $\mathrm{O}$ estudo destas mudanças e a proposição de novas estratégias de enfrentamento na defesa dos objetivos de pleno emprego, e, no caso de países em desenvolvimento, do crescimento econômico, se impõe como prioritário a qualquer um que se considere praticante da tradição keynesiana. A adesão a estes princípios gerais deveria se constituir, na minha visão, o critério de filiação à $\mathrm{AKB}$.

Finalmente, vale a pena notar que Keynes foi sempre um otimista. Sua crença no poder de persuasão de idéias corretas e na capacidade do público de escolher as políticas que mais lhe conviessem parecia inabalável. É a esperança deste autor que seja esta a atitude que marque a atuação da Associação Keynesiana Brasileira aqui fundada. 